Original article

\title{
Lipid-lowering drug prescriptions in a group of Colombian patients
}

Andrés Gaviria-Mendoza ${ }^{1,2}$, Manuel E. Machado-Duque ${ }^{1,2}$, Jorge E. Machado-Alba ${ }^{1}$

${ }^{1}$ Grupo de Investigación en Farmacoepidemiología y Farmacovigilancia, Universidad

Tecnológica de Pereira-Audifarma, S. A., Pereira, Colombia

${ }^{2}$ Grupo de Investigación en Biomedicina, Fundación Universitaria Autónoma de las Américas,

Pereira, Colombia

Introduction. Lipid-lowering drugs, especially statins, have shown great relevance in preventing and treating cardiovascular diseases.

Objective. To determine the prescription patterns of lipid-lowering drugs and the variables associated with their use in a Colombian population.

Materials and methods. This is a cross-sectional descriptive study. From a drugdispensing database of approximately 4.5 million Colombian health system affiliates, patients of all ages and both sexes treated with lipid-lowering agents (statins, fibrates, ezetimibe) were identified between January and March, 2017. Demographic, pharmacological and co-medication variables were included.

Results. In total, 103,624 patients were identified as being treated with lipid-lowering agents. The average age was 67.5 years, and $49.8 \%$ were 65 years or older. Women comprised $58.0 \%$ of the patients. Statins were the most used $(n=96,910 ; 93.5 \%)$, and atorvastatin $(n=80,812 ; 78.0 \%)$ and lovastatin $(n=12,621 ; 12.2 \%)$ were the most frequent. The mean atorvastatin dose was $30.3 \mathrm{mg} /$ day, and $49.9 \%$ of its users received presentations of $40 \mathrm{mg}$ or more. A total of $9,258(8.9 \%)$ patients received fibrates, and only $780(0.8 \%)$ were taking ezetimibe. Of this population, $94.9 \%$ were treated with lipid-lowering monotherapy, and $97.3 \%(n=100,813)$ had co-medication for their comorbidities, with the most frequent being antihypertensive (89.1\%), antiplatelet $(57.8 \%)$, antidiabetic $(31.5 \%)$ and antiulcerative agents (34.2\%).

Conclusions. Atorvastatin is currently the most frequently used lipid-lowering drug in this group of Colombian patients, especially in monotherapy and at doses close to the defined daily dose. Only half received high-intensity doses. New studies are required to verify the efficacy of these therapies.

Received: $24 / 10 / 18$

Accepted: $30 / 05 / 19$

Published: $12 / 06 / 19$

Citation:

Gaviria-Mendoza A, Machado-Duque ME, MachadoAlba JE. Lipid-lowering drug prescriptions in a group of Colombian patients.

Biomédica. 2019;39:759-68.

https://doi.org/10.7705/biomedica.4801

\section{Corresponding author:}

Jorge E. Machado-Alba, Grupo de Investigación en Farmacoepidemiología y Farmacovigilancia, Universidad Tecnológica de Pereira-Audifarma S. A. Calle $105 \mathrm{~N}^{\circ}$ 14-140, Pereira, Colombia Phone: (57) (310) 832 6970; fax: (576) 3137822 machado@utp.edu.co

\section{Author contributions:}

Jorge E. Machado-Alba: Data collection, data analysis, critical revision of the article and evaluation of the final version of the manuscript.

Manuel E. Machado-Duque: Data collection and data analysis.

Andrés Gaviria-Mendoza: Data collection and data analysis, and evaluation of the final version of the manuscript

Funding:

This work received funding from Sanofi, S. A.

Conflicts of interest:

The authors declare that they have no additional conflicts of interest for the realization of this work There was no intervention by Sanofi, S. A., in any stage of processing, analyzing or publishing the data.
Keywords: Dyslipidemias; ezetimibe; pharmacoepidemiology; hydroxymethylglutaryl-CoA reductase inhibitors; hypolipidemic agents; drug prescriptions.

\section{Patrones de prescripción de hipolipemiantes en pacientes de Colombia}

Introducción. Los fármacos hipolipemiantes, especialmente las estatinas, han demostrado gran relevancia para la prevención y el tratamiento de las enfermedades cardiovasculares. Objetivo. Determinar los patrones de prescripción de los fármacos hipolipemiantes y las variables asociadas con su uso en una población de Colombia.

Materiales y métodos. Se trata de un estudio descriptivo y transversal. A partir de una base de datos de dispensación de medicamentos de 4,5 millones de afiliados al sistema de salud de Colombia, se identificaron los pacientes de cualquier edad y sexo en tratamiento con hipolipemiantes (estatinas, fibratos, ezetimibe), entre enero y marzo de 2017. Se incluyeron variables demográficas, farmacológicas y de comedicaciones.

Resultados. Se identificaron 103.624 pacientes en tratamiento con hipolipemiantes. La edad promedio fue de 67,5 años y el $49,8 \%$ tenía 65 o más años. El 58,0 \% eran mujeres. Las estatinas fueron los más utilizados ( $n=96.910 ; 93,5 \%)$, siendo la atorvastatina $(n=80.812 ; 78,0 \%)$ y la lovastatina $(n=12.621 ; 12,2 \%)$ las más frecuentes. La dosis promedio de atorvastatina fue de $30,3 \mathrm{mg} /$ día y el $49,9 \%$ de sus usuarios recibía presentaciones de 40 mg o más. Un total de 9.258 (8,9\%) pacientes recibían fibratos y solo $780(0,8 \%)$ tomaban ezetimibe. El 94,9\% de casos recibió tratamiento en monoterapia hipolipemiante y el $97,3 \%(n=100.813)$ tenía comedicaciones para comorbilidades, siendo las más frecuentes antihipertensivos $(89,1 \%)$, antiagregantes plaquetarios (57,8\%), antidiabéticos $(31,5 \%)$ y antiulcerosos $(34,2 \%)$.

Conclusiones. La atorvastatina es actualmente el medicamento hipolipemiante más utilizado en este grupo de pacientes de Colombia, especialmente en monoterapia y a dosis cercanas a las definidas, aunque solo la mitad recibían dosis recibían dosis de alta intensidad. Se requieren nuevos estudios que verifiquen la efectividad de estos tratamientos.

Palabras clave: dislipidemias; ezetimiba; farmacoepidemiología; inhibidores de hidroximetilglutaril-CoA reductasas; hipolipemiantes; prescripciones de medicamentos. 
Cardiovascular disease is a primary cause of morbidity and mortality worldwide, and its incidence continues to rise due to aging populations and unhealthy lifestyles (1). Colombia is not exempt to this situation. From 2005 to 2014, cardiovascular disease accounted for up to $30 \%$ of the country's total deaths (2).

One of the primary risk factors associated with cardiovascular disease is dyslipidemia, which mainly includes altered total cholesterol levels and low-density lipoprotein (LDL) (3). Among the drugs useful for managing dyslipidemias are statins, fibrates and ezetimibe. Despite its effects on plasma lipid levels, the use of some of these pharmacological groups is lower than expected, even in high cardiocerebrovascular-risk populations $(4,5)$.

The last study on usage patterns for this drug group in Colombia was published in 2008, where the only statin identified was lovastatin, and gemfibrozil was the second most used drug, reaching 27\% (6). More molecules are now available in all lipid-lowering drug groups, and reports in Colombian populations show some changes in their prescriptions. For example, by the year 2013, atorvastatin had already displaced lovastatin as the most widely used statin drug $(7,8)$.

In the present work, we sought to determine the prescription patterns of lipid-lowering drugs in patients affiliated with the Sistema General de Seguridad Social en Salud (SGSSS) in 2017, considering the possible epidemiological changes in cardiovascular disease and the inclusion of new lipid-lowering medications in the benefit plan offered by health insurance entities (Benefit Plan Administrators) (9).

\section{Materials and methods}

\section{Study design}

A cross-sectional study was conducted on the prescription habits of lipid-lowering drugs. Information was obtained from a population database of approximately 4.5 million people affiliated with the SGSSS in five Benefit Plan Administrators of the contributory scheme, which corresponds to approximately $22.5 \%$ of the active population affiliated with this regime in the country and $9.3 \%$ of the Colombian population.

We analyzed prescribing data from patients treated with lipid-lowering drugs between January $1^{\text {st }}$. and March $31^{\text {st }}$., 2017 in all Colombian cities with reliable databases. We included data on individuals of all ages and sexes who had been prescribed lipid-lowering drugs and whose management was uninterrupted for at least three months to ensure that patients stably complied with the treatment, reflecting medication tolerance and adherence.

Medicine consumption information on the affiliated population was systematically obtained by the dispensing company (Audifarma, S. A.). Audifarma, S. A. is the largest drug dispensing company in Colombia. Information is generated at the time of dispensing and stored on a server with daily dispensing data (approximately 2.8 million formulas per month). To access the data, the Business Object tool is used on a platform in Oracle where all the drug claims are stored; and a database was designed with the following variables:

1. Sociodemographics included sex, age, and city.

2. Lipid-lowering drugs included statins (atorvastatin, cerivastatin, fluvastatin, lovastatin, pitavastatin, pravastatin, rosuvastatin, simvastatin), 
fibrates (bezafibrate, ciprofibrate, fenofibrate, gemfibrozil) and ezetimibe (alone or combined with statins). The dose and quantity delivered were recorded. The defined daily dose (DDD) was used as a unit of measurement for the drug use per the recommendations of the World Health Organization.

3. Co-medication was accepted as a surrogate indicator of chronic disease, considering the following circumstances: a) antidiabetics and insulins/ diabetes mellitus; b) antihypertensive and diuretic/arterial hypertension; c) anticoagulants/thromboembolic disorders; d) levothyroxine-antithyroid/thyroid pathology; e) nitrovasodilators/ischemic heart disease; f) anti-ulcers/acid-peptic disease; g) antiplatelet drugs/cardiovascular prevention.

\section{Bioethics}

The protocol was endorsed by the Bioethics Committee of the Universidad Tecnológica de Pereira and was classified in the category of "risk-free research". Patients' personal data were not used, and their identities were safeguarded per the recommendations of the Declaration of Helsinki.

\section{Data analyses}

Descriptive statistics were used to analyze the data using the statistical package SPSS ${ }^{\mathrm{TM}}$, version 24.0 (IBM, USA) for Windows. Bivariate tests were also performed, such as Student's t test to compare quantitative variables, and $\mathrm{c}^{2}$ for categorical variables. We prepared binary logistic regression models using lipid-lowering drug use alone or in combination therapy (yes/ no) and the need for co-medication (yes/no) as dependent variables. The covariates in these models included age, sex and the variables that were significantly associated with the dependent variables in the bivariate analyses. The statistical significance level was $p<0.05$.

\section{Results}

We identified 103,624 patients affiliated with the SGSSS being treated with lipid-lowering drugs continuously during the study period. The average age was $67.5 \pm 12.1$ years (range: 18-105 years), and the sex distribution showed that $60,098(58.0 \%)$ were women. People aged 65 years and older represented $49.8 \%(n=51,615)$ of the population (figure 1$)$.

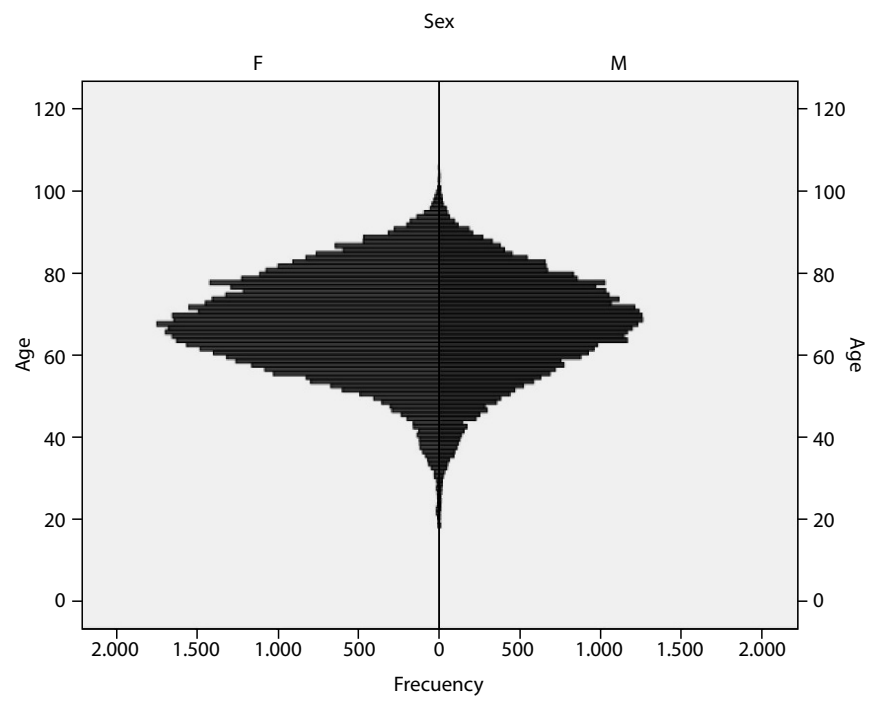

Figure 1. Distribution of 103,624 patients treated with lipid-lowering drugs, by age and sex, Colombia, 2017 
Of the population, $93.5 \%(n=96,910)$ received treatment with some statin, with atorvastatin being the most used $(n=80,812 ; 78.0 \%$ of the total population), followed by lovastatin with 12,621 patients (12.2\%). The main presentations dispensed were atorvastatin tablets $20 \mathrm{mg}(\mathrm{n}=42,389 ; 52.4 \%$ of those with atorvastatin) and $40 \mathrm{mg}(\mathrm{n}=39,724 ; 49.2 \%)$, but 3,210 (4.0\%) received $10 \mathrm{mg}$, and 634 received $80 \mathrm{mg}(0.8 \%)$. All lovastatin was prescribed as $20 \mathrm{mg}$. Only 4 patients received pitavastatin, and no formulations of cerivastatin, fluvastatin and pravastatin were found.

A total of $9,258(8.9 \%)$ patients received fibrates, mainly gemfibrozil $(n=8,242 ; 8.0 \%$ of the total subjects). Seven hundred eighty patients $(0.8 \%)$ used some form of ezetimibe. Table 1 shows the prescription patterns of each of these drug groups.

The relationship between the average dose administered and the DDD varied greatly, with values from 0.44 for lovastatin to 2.53 for rosuvastatin (table 1). A total of 40,358 patients with atorvastatin (38.9\% of the total population and $49.9 \%$ of those with atorvastatin) were receiving presentations of $40 \mathrm{mg}$ or more, while 5,274 patients received rosuvastatin $20 \mathrm{mg}$ or more ( $5.1 \%$ of all patients and $94.0 \%$ of rosuvastatin users).

\section{Monotherapy versus combination therapy}

A total of 98,355 patients $(94.9 \%)$ used a single lipid-lowering drug during the study period, while 5,190 (5.0\%) used a combination of two drugs, and 79 cases received three medications. Figure 2 shows the distribution of the main lipid-lowering agents used by monotherapy or combination therapy.

The most frequent association was atorvastatin plus gemfibrozil $(n=1,986$ patients, $1.9 \%$ of all patients). Multivariate analysis of the relationship between the use of combination lipid-lowering therapy and other variables showed that the concomitant use of antidiabetics, thiazide diuretics, minoxidil and proton pump inhibitors increased the probability of receiving therapy with more than one lipid-lowering drug. In contrast, being 65 years of age or older and using apixaban reduced this probability (table 2 ).

Table 1. Prescription patterns of lipid-lowering drugs used in 103,624 patients in Colombia, 2017

\begin{tabular}{|c|c|c|c|c|c|c|c|}
\hline \multirow{2}{*}{ Medication } & \multicolumn{2}{|c|}{ Prescription/users } & \multicolumn{2}{|c|}{ Dose (mg/day) } & \multirow{2}{*}{ DDD } & \multirow{2}{*}{$\begin{array}{l}\text { Female:Male } \\
\text { ratio }\end{array}$} & \multirow{2}{*}{$\begin{array}{c}\text { Mean age } \\
\text { (years) }\end{array}$} \\
\hline & Patients & $\%$ & Mean & Median & & & \\
\hline Statins* & 96,910 & 93.5 & & & & $1.4: 1$ & 67.8 \\
\hline Atorvastatin & 80,812 & 78.0 & 30.3 & 26.7 & 1.52 & $1.4: 1$ & 67.8 \\
\hline Lovastatin & 12,621 & 12.2 & 19.9 & 20.0 & 0.44 & $1.7: 1$ & 68.2 \\
\hline Rosuvastatin & 5,609 & 5.4 & 25.3 & 18.7 & 2.53 & 1.3:1 & 65.6 \\
\hline Simvastatin & 343 & 0.3 & 29.3 & 24.9 & 0.98 & 1.1:1 & 67.2 \\
\hline Fibrates & 9,258 & 8.9 & & & & 1.0:1 & 63.2 \\
\hline Gemfibrozil & 8,242 & 8.0 & 628.6 & 600.0 & 0.52 & 1.1:1 & 63.5 \\
\hline Fenofibrate & 591 & 0.6 & 186.4 & 200.0 & 0.93 & $0.8: 1$ & 61.3 \\
\hline Ciprofibrate & 471 & 0.5 & 97.5 & 100.0 & 0.97 & $0.7: 1$ & 60.6 \\
\hline Ezetimibe & 780 & 0.8 & 9.0 & 9.3 & 0.90 & $0.9: 1$ & 65.3 \\
\hline Ezetimibe $10 \mathrm{mg}$ & 262 & 0.3 & 8.1 & 6.7 & 0.67 & $1.0: 1$ & 65.0 \\
\hline Combined presentations & 524 & 0.5 & 9.3 & 9.3 & 0.93 & $0.9: 1$ & 65.6 \\
\hline
\end{tabular}

DDD: average ratio between the prescribed daily dose and the defined daily dose.

* Only 4 patients were receiving pitavastatin during the study time. 


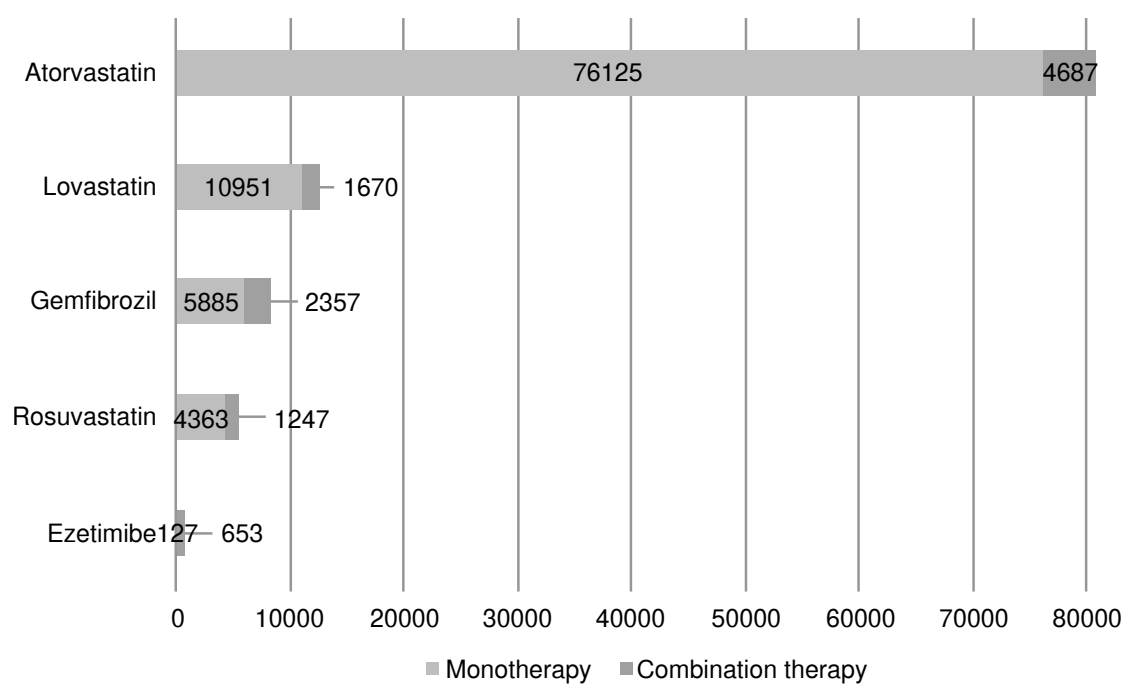

Figure 2. Frequency of prescription of the main lipid-lowering drugs used, alone or in combination therapy, Colombia, 2017

Table 2. Variables associated with combined lipid-lowering therapy in binary logistic regression models, Colombia, 2017

\begin{tabular}{lrrrc}
\hline \multirow{2}{*}{ Variables } & \multirow{2}{*}{ Sig. } & OR & \multicolumn{2}{c}{$95 \%$ Cl } \\
\cline { 4 - 5 } & & & Lower & Upper \\
\hline Age $\geq 65$ years & $<0.01$ & 0.75 & 0.70 & 0.80 \\
Male sex & 0.10 & 1.05 & 0.99 & 1.12 \\
Use of: & & & & \\
$\quad$ Antidiabetics & $<0.01$ & 1.12 & 1.05 & 1.20 \\
Thiazide diuretics & $<0.01$ & 1.18 & 1.10 & 1.27 \\
Alpha-blockers & 0.09 & 0.87 & 0.74 & 1.02 \\
Minoxidil & 0.04 & 2.41 & 1.03 & 5.68 \\
Apixaban & 0.04 & 0.48 & 0.24 & 0.96 \\
Proton pump inhibitors & $<0.01$ & 1.16 & 1.09 & 1.24 \\
Living in Cali city & $<0.01$ & 1.43 & 1.30 & 1.57 \\
Constant & 0.00 & 0.05 & & \\
\hline
\end{tabular}

Sig.: Significance; OR: Odds ratio; $95 \% \mathrm{Cl}: 95 \%$ confidence interval

\section{Co-medication}

Most study patients $(97.3 \%, n=100,813)$ used some co-medication. The average number of co-medications per patient was $4.0 \pm 2.0$ (range: 0-14 different drugs). The drugs for other comorbidities most frequently identified were antihypertensive drugs ( $n=92,338 ; 89.1 \%)$, antiplatelet agents $(n=59,890$; $57.8 \%$, and $97.8 \%$ corresponded to acetylsalicylic acid), antidiabetics ( $n=32,609 ; 31.5 \%$, of which $30.4 \%$ used insulins) and antiulcer drugs ( $n=35,397 ; 34.2 \%$, where $92.2 \%$ corresponded to proton pump inhibitors).

We identified 28,562 patients (27.6\%) consuming antihypertensive and antidiabetic medications concomitantly. Of diabetic patients, $87.6 \%$ received an antihypertensive, while $30.9 \%$ of hypertensive patients used antidiabetics.

In the antihypertensive group, 41,510 patients ( $40.1 \%$ of the total patients, $45.0 \%$ of those with antihypertensive drugs) received a combination of two drugs in this group, and 17,589 (17.0\%) received three. The most prescribed group was angiotensin II-receptor antagonists (especially losartan) in 65,416 patients (63.1\%), followed by $\beta$-adrenergic blockers (33.3\%), calcium channel blockers $(32.9 \%)$, thiazide diuretics (23.3\%) and angiotensin-converting enzyme inhibitors (17.2\%). 
Other medications included those used to treat thyroid disease $(n=18,242$, $17.6 \%)$, loop diuretics ( $n=15,063,14.5 \%)$, aldosterone inhibitors $(n=5,501$, $5.3 \%)$, anticoagulants $(n=3,405,3.3 \%)$, nitrovasodilators $(n=1,326,1.3 \%)$ and arterial vasodilators $(n=73,0.1 \%)$. Table 3 shows the sociodemographic and pharmacological variables of patients receiving lipid-lowering drugs by comedications or comorbidities.

Multivariate analysis of the outcome of receiving some co-medication in patients being treated with lipid-lowering drugs indicated that being 65 years of age or older and using non-combined presentations of lovastatin, atorvastatin, rosuvastatin and fibrates were associated with a higher probability of receiving co-medication. Ezetimibe use was associated with a lower probability of receiving co-medication (table 4).

\section{Comparison between cities}

Demographic variables and some prescription indicators were compared among the 105 Colombian cities included in this study. The different characteristics and proportions of lipid-lowering drug use in the eight main cities are summarized in table 5.

Table 3. Comparison of lipid-lowering prescriptions according to comorbidity, Colombia, 2017

\begin{tabular}{|c|c|c|c|c|c|c|c|c|}
\hline Variable & $\begin{array}{c}\text { Anti } \\
\text { hypertensive } \\
n=92,338 \\
\end{array}$ & $\begin{array}{c}\text { Antiplatelet } \\
\text { drugs } \\
n=59,890 \\
\end{array}$ & $\begin{array}{l}\text { Antidiabetics } \\
\qquad n=32,609 \\
\end{array}$ & $\begin{array}{c}\begin{array}{c}\text { Antiulcer } \\
\text { drugs }\end{array} \\
n=35,397\end{array}$ & $\begin{array}{c}\text { Thyroid } \\
\text { hormone } \\
n=18,242 \\
\end{array}$ & $\begin{array}{c}\begin{array}{c}\text { Loop } \\
\text { diuretic }\end{array} \\
n=15,063\end{array}$ & $\begin{array}{c}\text { Aldosterone } \\
\text { inhibitors } \\
n=5,501 \\
\end{array}$ & $\begin{array}{c}\text { Anticoagulants } \\
\qquad n=3,405\end{array}$ \\
\hline Mean age (years) & 68.1 & 68.8 & 67.3 & 69.5 & 69.5 & 73.4 & 70.1 & 71.4 \\
\hline Women (\%) & $53,480(57.9)$ & $32,478(54.2)$ & $18,290(56.1)$ & $22,753(64.3)$ & 13,197 (72.3) & 8,619 (57.2) & 2,692 (48.9) & $1,650(48.5)$ \\
\hline Polytherapy (\%) & $4,659 \quad(5.0)$ & $3,068 \quad(5.1)$ & $1,793 \quad(5.5)$ & $1,924 \quad(5.4)$ & $969 \quad(5.3)$ & 742 (4.9) & $272 \quad(4.9)$ & $153(4.5)$ \\
\hline \multicolumn{9}{|l|}{ Prescription- n (\%) } \\
\hline Statins & 87,167 (94.4) & $56,878(95.0)$ & 30,477 (93.5) & 33,515 (94.7) & 17,305 (94.9) & $14,432(95.8)$ & $5,391(98.0)$ & $3,344(98.2)$ \\
\hline Atorvastatin & 72,875 (78.9) & $48,175(80.4)$ & 25,739 (78.9) & $28,547(80.6)$ & 14,475 (79.3) & $12,464(82.7)$ & 4,757 (86.5) & $2,915(85.6)$ \\
\hline Lovastatin & $11,406(12.4)$ & $6,841(11.4)$ & 3,484 (10.7) & 3,632 (10.3) & $2,316(12.7)$ & 1,548 (10.3) & $374 \quad(6.8)$ & $262(7.7)$ \\
\hline Rosuvastatin & $4,904 \quad(5.3)$ & $3,222 \quad(5.4)$ & $1,939 \quad(5.9)$ & $2,159 \quad(6.1)$ & $910 \quad(5.0)$ & 741 (4.9) & $396 \quad(7.2)$ & $252(7.4)$ \\
\hline Simvastatin & $234 \quad(0.3)$ & $152(0.3)$ & $99 \quad(0.3)$ & $97 \quad(0.3)$ & $78 \quad(0.4)$ & $34 \quad(0.2)$ & $25 \quad(0.5)$ & $15 \quad(0.4)$ \\
\hline Fibrates & $7,437 \quad(8.1)$ & $4,475 \quad(7.5)$ & $3,081 \quad(9.4)$ & $2,830 \quad(8.0)$ & $1,407 \quad(7.7)$ & $1,006 \quad(6.7)$ & $205 \quad(3.7)$ & $102(3.0)$ \\
\hline Gemfibrozil & $6,891 \quad(7.5)$ & $4,136 \quad(6.9)$ & $2,729 \quad(8.4)$ & $2,571 \quad(7.3)$ & $1,266 \quad(6.9)$ & $924 \quad(6.1)$ & $168 \quad(3.1)$ & $76 \quad(2.2)$ \\
\hline Fenofibrate & $327 \quad(0.4)$ & $196 \quad(0.3)$ & $222(0.7)$ & $153(0.4)$ & $73 \quad(0.4)$ & $48 \quad(0.3)$ & $20 \quad(0.4)$ & $18(0.5)$ \\
\hline Ciprofibrate & $254 \quad(0.3)$ & $164 \quad(0.3)$ & $154 \quad(0.5)$ & $122(0.3)$ & $75 \quad(0.4)$ & $42 \quad(0.3)$ & $18 \quad(0.3)$ & $9 \quad(0.3)$ \\
\hline Ezetimibe & $494 \quad(0.5)$ & $339 \quad(0.6)$ & $211 \quad(0.6)$ & $196 \quad(0.6)$ & $132(0.7)$ & $62(0.4)$ & $51 \quad(0.9)$ & $34 \quad(1.0)$ \\
\hline Ezetimibe $10 \mathrm{mg}$ & $156 \quad(0.2)$ & $113(0.2)$ & $58 \quad(0.2)$ & $62(0.2)$ & $26 \quad(0.1)$ & $18 \quad(0.1)$ & $19(0.3)$ & $12(0.4)$ \\
\hline Combined presentations & $339(0.4)$ & $227 \quad(0.4)$ & $154(0.5)$ & $135(0.4)$ & $106(0.6)$ & $45 \quad(0.3)$ & $32(0.6)$ & $22(0.6)$ \\
\hline
\end{tabular}

Table 4. Variables associated with lipid-lowering therapy with co-medication in binary logistic regression models, Colombia, 2017

\begin{tabular}{|c|c|c|c|c|}
\hline \multirow{2}{*}{ Variables } & \multirow{2}{*}{ Sig. } & \multirow{2}{*}{ OR } & \multicolumn{2}{|c|}{$95 \% \mathrm{Cl}$} \\
\hline & & & Lower & Upper \\
\hline Age $\geq 65$ years & $<0.01$ & 3.54 & 3.22 & 3.88 \\
\hline Male sex & 0.22 & 1.05 & 0.97 & 1.15 \\
\hline \multicolumn{5}{|l|}{ Use of: } \\
\hline Lovastatin & $<0.01$ & 6.70 & 5.22 & 8.60 \\
\hline Atorvastatin & $<0.01$ & 8.53 & 6.86 & 10.60 \\
\hline Simvastatin & 0.52 & 0.76 & 0.33 & 1.77 \\
\hline Rosuvastatin & $<0.01$ & 3.32 & 2.60 & 4.24 \\
\hline Ezetimibe & $<0.01$ & 0.24 & 0.17 & 0.33 \\
\hline Fibrates & $<0.01$ & 1.64 & 1.32 & 2.04 \\
\hline Constant & 0.00 & 3.32 & & \\
\hline
\end{tabular}

Sig: Significance; OR: Odds ratio; $95 \% \mathrm{Cl}: 95 \%$ confidence interval 
Table 5. Comparison of demographic variables and indicators of lipid-lowering prescriptions in eight Colombian cities, 2017

\begin{tabular}{|c|c|c|c|c|c|c|c|c|c|}
\hline & $\begin{array}{c}\text { Bogotá } \\
n=32,670\end{array}$ & $\begin{array}{l}\text { Pereira } \\
n=9,378\end{array}$ & $\begin{array}{c}\text { Cali } \\
n=8,969\end{array}$ & $\begin{array}{c}\text { Cartagena } \\
n=6,022\end{array}$ & $\begin{array}{c}\text { Barranquilla } \\
n=5,520\end{array}$ & $\begin{array}{c}\text { Manizales } \\
\mathrm{n}=4,155\end{array}$ & $\begin{array}{l}\text { Ibagué } \\
n=3,488\end{array}$ & $\begin{array}{l}\text { Palmira } \\
n=3,174\end{array}$ & $\begin{array}{l}\text { Colombia } \\
n=103,624\end{array}$ \\
\hline Mean age (years) & 64.8 & 68.8 & 71.9 & 66.1 & 67.8 & 66.6 & 67.0 & 70.8 & 67.5 \\
\hline Women (\%) & $18,921(57.9)$ & $5,504(58.7)$ & $5,389(60.1)$ & $3,370(56.0)$ & $3,126(56.6)$ & $2,512(60.5)$ & $2,081(59.7)$ & $1,933(60.9)$ & $60,098(58.0)$ \\
\hline Polytherapy (\%) & $1,570 \quad(4.8)$ & $348 \quad(3.7)$ & $593 \quad(6.6)$ & $260 \quad(4.3)$ & $285 \quad(5.2)$ & $165 \quad(4.0)$ & $163(4.7)$ & 202 (6.4) & $5,269 \quad(5.1)$ \\
\hline Comedication (\%) & $31,403(96.1)$ & $9176(97.8)$ & $8,683(96.8)$ & $5,934(98.5)$ & $5,449(98.7)$ & $4,023(96.8)$ & $3,428(98.3)$ & 3,119 (98.3) & $100,813(97.3)$ \\
\hline \multicolumn{10}{|l|}{ Prescription - n (\%) } \\
\hline Statins & 30,783 (94.2) & $9,000(96.0)$ & $8,104(90.4)$ & $5,795(96.2)$ & $5,313(96.3)$ & $3,973(95.6)$ & $3,214(92.1)$ & $2,795(88.1)$ & $96,910(93.5)$ \\
\hline Atorvastatin & 25,131 (76.9) & $7,290(77.7)$ & $7,136(79.6)$ & 4,677 (77.7) & 4,596 (83.3) & $2,811(67.7)$ & $2,618(75.1)$ & $2,274(71.6)$ & $80,812(78.0)$ \\
\hline Lovastatin & $4,774(14.6)$ & $1,375(14.7)$ & $1,019(11.4)$ & $289 \quad(4.8)$ & $259 \quad(4.7)$ & $1,079(26.0)$ & $426(12.2)$ & $497(15.7)$ & $1,2621(12.2)$ \\
\hline Rosuvastatin & $1,571 \quad(4.8)$ & $506 \quad(5.4)$ & $105(1.2)$ & $982(16.3)$ & $604(10.9)$ & 169 (4.1) & $241 \quad(6.9)$ & 92 (2.9) & $5,609 \quad(5.4)$ \\
\hline Simvastatin & $171 \quad(0.5)$ & $25 \quad(0.3)$ & $37 \quad(0.4)$ & $9(0.1)$ & $10 \quad(0.2)$ & $2(0.0)$ & $3(0.1)$ & $13(0.4)$ & $343 \quad(0.3)$ \\
\hline Fibrates & $2,549 \quad(7.8)$ & $507 \quad(5.4)$ & $1,199(13.4)$ & $318 \quad(5.3)$ & $332(6.0)$ & $249 \quad(6.0)$ & $359(10.3)$ & $480(15.1)$ & $9,258 \quad(8.9)$ \\
\hline Gemfibrozil & $2,269 \quad(6.9)$ & $433(4.6)$ & $1,083(12.1)$ & $295 \quad(4.9)$ & $300 \quad(5.4)$ & $200(4.8)$ & $341 \quad(9.8)$ & $380(12.0)$ & $8,242 \quad(8.0)$ \\
\hline Fenofibrate & $148 \quad(0.5)$ & $55 \quad(0.6)$ & $67 \quad(0.7)$ & $17(0.3)$ & $15(0.3)$ & $28 \quad(0.7)$ & $4 \quad(0.1)$ & $77 \quad(2.4)$ & $591 \quad(0.6)$ \\
\hline Ciprofibrate & $138 \quad(0.4)$ & $22(0.2)$ & $50 \quad(0.6)$ & $7 \quad(0.1)$ & $19(0.3)$ & $22(0.5)$ & $17(0.5)$ & $31 \quad(1.0)$ & $471 \quad(0.5)$ \\
\hline Ezetimibe & $314(1.0)$ & $49 \quad(0.5)$ & $124(1.4)$ & $22(0.4)$ & $14 \quad(0.3)$ & $18(0.4)$ & $3(0.1)$ & 44 (1.4) & $780 \quad(0.8)$ \\
\hline Ezetimibe $10 \mathrm{mg}$ & $57 \quad(0.2)$ & $23(0.2)$ & $72(0.8)$ & $8(0.1)$ & $2(0.0)$ & $9(0.2)$ & $1(0.0)$ & $13(0.4)$ & $262(0.3)$ \\
\hline Combined presentations & $257 \quad(0.8)$ & $26 \quad(0.3)$ & $56 \quad(0.6)$ & $14 \quad(0.2)$ & $12(0.2)$ & $9(0.2)$ & $2(0.1)$ & $31 \quad(1.0)$ & $524 \quad(0.5)$ \\
\hline
\end{tabular}

\section{Discussion}

In the present work, the utilization profile of the main lipid-lowering drugs used in an insured population of the Colombian health system was described, finding large differences from data previously reported in the country.

The average age of those who use these medications is consistent with the profile of dyslipidemia and cardiovascular disease $(2,10)$. The predominance of females attracts attention because men experience greater mortality and more years of life potentially lost due to this group of pathologies (2), although in Colombia, mixed dyslipidemia has been described as the most common and that it presents more frequently in women (10).

During the study period, the most used drug group was the statins, encompassing over $90 \%$ of the total prescriptions, while fibrates only accounted for approximately $9 \%$. This shows an important change regarding the 2008 data, where statins, despite also being the most consumed, only encompassed $71 \%$ of total prescriptions and fibrates comprised $27 \%$ (6). As mentioned above, for 2008 , the dominant statin was lovastatin because it was the only one included on the SGSSS benefit plan's drug list. The change in the prescription pattern to atorvastatin, until now the dominant drug, was likely due to its inclusion in the benefit plan (9) and because higher doses can be achieved, which improves the therapy's intensity and therefore the expected efficacy (11-13).

This change towards increased atorvastatin prescriptions is also supported by previous national study results, which found that patients treated with lovastatin were less likely to achieve metabolic control (although it was used at doses lower than those recommended, similar to the present study) (8). In addition, atorvastatin has been identified as the most cost-effective option for patients with dyslipidemia in the Colombian health context when moderate to high intensity treatments are required (14). When comparing these results with studies from other countries, atorvastatin has also been the most prescribed in Taiwan, but only at 37\% (15), whereas research in Italy and Brazil found a predominance of simvastatin $(16,17)$. 
In the present study, more than a third of the population was receiving statins at high intensity doses by international standards (atorvastatin 40$80 \mathrm{mg}$, rosuvastatin 20-40 mg) (12). In a sample of Colombian patients receiving lipid-lowering drugs, according to the Framingham scale, $94 \%$ of these patients had a moderate to high cardiovascular risk (10), which is why it would be expected that more patients in the study were receiving high doses of these drugs in addition to the indications of national and international management guidelines $(12,13)$.

Lipid-lowering drug use in combination therapy was $5 \%$, which is similar to previous national reports (8) and works published in France (18) and the United States (19). Concomitantly using statins with fibrates is usually avoided due to the increased risk of adverse reactions, which has been documented in pharmacoepidemiological studies (19); therefore, the high monotherapy frequency seems appropriate, although in adequately selected patients with residual cardiovascular risk, combination therapy may be a therapeutic option of interest to achieve goals (20) with fibrates as well as ezetimibe (21), and more recently with new therapeutic options such as PCSK9 inhibitors (3).

The comorbidities and co-medications found in the study population are consistent with the profile associated with patients requiring lipid-lowering drugs. Therefore, antihypertensive, antiplatelet and antidiabetic agents were the dominant co-medications, as has been described in other studies (8). It is striking that in this patient group, antiplatelet agents reached a usage near $60 \%$, much higher than the value of $3.8 \%$ reported in 2008 , indicating an improvement in preventing cardiovascular risk among this type of patients (6).

The worldwide tendency is to increase prescriptions of lipid-lowering drugs in patients with diabetes mellitus (22), because the recommended use of statins is growing in patients with this comorbidity as a routine step for prevention of cardiovascular events, which was also identified in this study (increasing from $20 \%$ in 2008 to $32 \%$ in 2017) (6). The high use of antiulcerative drugs has been described previously, especially in chronic disease populations, often without a clear indication (23), although in this case, it can be explained by the high prescription of antiplatelet agents in elderly patients.

Another interesting aspect is the relationship found between ezetimibe use and the lower probability of having co-medications, especially because ezetimibe has been described as a useful medication to achieve goals in patients with dyslipidemia who also have multiple comorbidities (24). Residual confounders not considered during the study may explain this relationship, such as the patient's educational levels or socioeconomic statuses (25), aspects of health and insurance services, preferences of prescribing physicians or the presence of clinical inertia to reach goals in dyslipidemia in patients with multiple pathologies (26).

Differences between prescription profiles in different cities (for example, variations in the prevalence of rosuvastatin use) are frequent in pharmacoepidemiological studies (6) and have been associated with local differences in health services, medical training or inhabitants' characteristics (27).

This research has some limitations. Because the results came from dispensing databases, and clinical records were not consulted, variables such as patients' cardiovascular risk, lipid profiles, efficacy or the presence of adverse reactions were not analyzed. Likewise, the patterns found are applicable only to populations with insurance characteristics similar to the 
study subjects. New research is required to determine detailed aspects of using these drugs, for example, by the indication of treatment in the field of primary and secondary cardiovascular disease prevention.

The prescription patterns identified in this study highlight that the main lipid-lowering drug dispensed in Colombia is atorvastatin, especially in monotherapy and at doses close to DDD.

Regarding previous analyses, the prescriptions differed considerably, likely due to modifications in the drugs included in the benefit plans and the evidence presented in different clinical guides, highlighting the increase in useful co-medications for cardiovascular prevention such as antiplatelet drugs.

These data may be useful for professionals and health administrators to define behaviors related to managing cardiovascular risk in the Colombian population, since there seems to be an opportunity for improvement related to a probable underuse of statins at high doses in patients who require them. The adequate management of dyslipidemias can have a long-term impact on public health by reducing cardiovascular risk, morbidity and mortality secondary to ischemic events, heart failure and, in addition, the costs derived from their attention.

\section{Acknowledgments}

To Soffy López and Carlos Tovar by data base collection.

\section{References}

1. Lozano R, Naghavi M, Foreman K, Lim S, Shibuya K, Aboyans V, et al. Global and regional mortality from 235 causes of death for 20 age groups in 1990 and 2010: A systematic analysis for the Global Burden of Disease Study 2010. Lancet. 2012;380:2095-128. https://doi.org/10.1016/s0140-6736(12)61728-0

2. Ministerio de Salud y Protección Social. Análisis de situación de salud (ASIS). Colombia, 2016. Accessed: January 7, 2017. Available from: https://www.minsalud.gov.co/sites/rid/ Lists/BibliotecaDigital/RIDE/VS/ED/PSP/asis-colombia-2016.pdf

3. Jellinger PS, Handelsman Y, Rosenblit PD, Bloomgarden ZT, Fonseca VA, Garber AJ, et al. American Association of Clinical Endocrinologists and American College of Endocrinology guidelines for management of dyslipidemia and prevention of cardiovascular disease. Endocr Pract. 2017;23:1-87. https://doi.org/10.4158/EP171764.APPGL

4. Turner GM, Calvert M, Feltham MG, Ryan R, Fitzmaurice D, Cheng KK, et al. Underprescribing of prevention drugs and primary prevention of stroke and transient ischaemic attack in UK general practice: A retrospective analysis. PLoS Med. 2016;13:e1002169. https://doi.org/10.1371/journal.pmed.1002169

5. Kulenovic I, Mortensen MB, Bertelsen J, May O, Dodt KK, Kanstrup H, et al. Statin use prior to first myocardial infarction in contemporary patients: Inefficient and not gender equitable. Prev Med. 2016;83:63-9. https://doi.org/10.1016/j.ypmed.2015.12.001

6. Machado JE, Moncada JC, Mesa G. Prescription patterns for antilipidemic drugs in a group of Colombian patients. Rev Panam Salud Pública. 2008;23:179-87.

7. Machado-Alba JE, Murillo-Muñoz MM, Machado-Duque ME. Effectiveness of lipid-lowering therapy among a sample of patients in Colombia. Rev Panam Salud Pública. 2013;33:383-90.

8. Machado-Alba JE, Machado-Duque ME, Yepes MC, Manrique S, Tobón LM. Tratamiento hipolipemiante y su efectividad en pacientes de cuatro ciudades colombianas. Acta Med Colomb. 2016;41:181-6.

9. Machado-Alba JE, Torres D, Portilla A, Ruiz AF. Results of the inclusion of new medications in the obligatory health system plan in Colombia, 2012-2013. Value Health Reg Issues. 2015;8:28-35. https://doi.org/10.1016/j.vhri.2015.02.002

10. Machado-Alba JE, Machado-Duque ME. Prevalencia de factores de riesgo cardiovascular en pacientes con dislipidemia afiliados al sistema de salud en Colombia. Rev Peru Med Exp Salud Pública. 2013;30:205-11. 
11. Rodríguez F, Maron DJ, Knowles JW, Virani SS, Lin S, Heidenreich PA. Association between intensity of statin therapy and mortality in patients with atherosclerotic cardiovascular disease. JAMA Cardiol. 2017;2:47-54. https://doi.org/10.1001/jamacardio.2016.4052

12. US Preventive Services Task Force, Bibbins-Domingo K, Grossman DC, Curry SJ, Davidson KW, Epling JW Jr, et al. Statin use for the primary prevention of cardiovascular disease in adults: US Preventive Services Task Force Recommendation Statement. JAMA 2016;316:1997-2007. https://doi.org/10.1001/jama.2016.15450

13. Muñoz O, García ÁA, Fernández DG, Higuera AM, Ruiz ÁJ, Aschner P, et al. Guía de práctica clínica para la prevención, detección temprana, diagnóstico, tratamiento y seguimiento de las dislipidemias: tratamiento farmacológico con estatinas. Rev Colomb Cardiol. 2015;22:14-21. https://doi.org/10.1016/j.rccar.2015.02.001

14. Rosselli D, Castaño N, Arciniegas J-A, García ÁA, Muñoz Ó-M, Gómez-Restrepo C. Costeffectiveness of statins for the treatment of dyslipidemia in Colombia. Acta Med Colomb. 2015;40:118-24.

15. Hsieh HC, Hsu JC, Lu CY. 10-year trends in statin utilization in Taiwan: A retrospective study using Taiwan's National Health Insurance Research Database. BMJ Open. 2017;7:e014150. https://doi.org/10.1136/bmjopen-2016-014150

16. Ferrajolo C, Arcoraci V, Sullo MG, Rafaniello C, Sportiello L, Ferrara R, et al. Pattern of statin use in southern italian primary care: Can prescription databases be used for monitoring long-term adherence to the treatment? PLoS One. 2014;9:e102146. https://doi.org/10.1371/journal.pone.0102146

17. Cunico C, Picheth G, Correr CJ, Scartezini M. Assessing the adherence to and the therapeutic effectiveness of hypolipidemic agents in a population of patients in Brazil: A retrospective cohort study. Pharm Pract (Granada). 2014;12:378.

18. Ferrières J, Gousse ET-L, Fabry C, Hermans MP. Assessment of lipid-lowering treatment in France - The CEPHEUS study. Arch Cardiovasc Dis. 2008;101:557-63. https://doi.org/:10.1016/j.acvd.2008.08.006

19. Enger C, Gately R, Ming EE, Niemcryk SJ, Williams L, McAfee AT. Pharmacoepidemiology safety study of fibrate and statin concomitant therapy. Am J Cardiol. 2010;106:1594-601. https://doi.org/10.1016/j.amjcard.2010.07.041

20. Fievet $\mathrm{C}$, Staels B. Combination therapy of statins and fibrates in the management of cardiovascular risk. Curr Opin Lipidol. 2009;20:505-11. https://doi.org/10.1097/MOL.0b013e328332e9ef

21. Tenenbaum A, Fisman EZ, Motro M, Adler Y. Optimal management of combined dyslipidemia: What have we behind statins monotherapy? Adv Cardiol. 2008;45:127-53. https://doi.org/10.1159/0000115192

22. Pauff BR, Jiroutek MR, Holland MA, Sutton BS. Statin prescribing patterns: An analysis of data from patients with diabetes in the National Hospital Ambulatory Medical Care Survey Outpatient Department and National Ambulatory Medical Care Survey Databases, 20052010. Clin Ther. 2015;37:1329-39. https://doi.org/10.1016/j.clinthera.2015.03.020

23. Machado-Alba J, Fernández A, Castrillón JD, Campo CF, Echeverri LF, Gaviria A, et al. Prescribing patterns and economic costs of proton pump inhibitors in Colombia. Colomb Med. 2013;44:13-8.

24. Lin Wu FL, Wang J, Ho W, Chou CH, Wu YJ, Choo DW, et al. Effectiveness of a combination of ezetimibe and statins in patients with acute coronary syndrome and multiple comorbidities: A 6-year population-based cohort study. Int J Cardiol. 2017;233:43-51. https://doi.org/10.1016/j.ijcard.2017.02.006

25. Wallach-Kildemoes $\mathrm{H}$, Hansen $\mathrm{EH}$. Sociodemographic and diagnostic characteristics of prescribing a second-line lipid-lowering medication: Ezetimibe used as initial medication, switch from statins, or add-on medication. Eur J Clin Pharmacol. 2015;71:1245-54. https://doi.org/10.1007/s00228-015-1907-y

26. Sinnott C, Hugh SM, Boyce MB, Bradley CP. What to give the patient who has everything? A qualitative study of prescribing for multimorbidity in primary care. $\mathrm{Br} \mathrm{J}$ Gen Pract. 2015;65:e184-91. https://doi.org/10.3399/bjgp15X684001

27. Juanes VG, Villar MC, González SF, Gómez JA, Alcántara MC, de Marino Gómez-Sandoval $\mathrm{M}$, et al. Análisis del consumo de medicamentos utilizando indicadores de calidad en la prescripción. Aten Primaria. 2000;25:618-24. 